\title{
Evaluation on simulative transportation and storage quality of sweet cherry by different varieties based on principal component analysis
}

\author{
Xiqing FU ${ }^{1}$ (D), Jiayang SUN ${ }^{1}$, Chunmao $\mathrm{LYU}^{1 \star}$, Xianjun MENG ${ }^{1}, \mathrm{He} \mathrm{GUO}^{1}$, Dan YANG ${ }^{1}$
}

\begin{abstract}
To determine the effect of transportation vibration on the nutritional quality and antioxidant activity of sweet cherry fruits in the process of cold chain transportation. Two kinds of sweet cherry "Summit" and "Nanyang" with different storage and transportation resistance were used as experimental materials. The results showed that the content of soluble solids, titratable acids and vitamin C in sweet cherry fruits were significantly reduced, while the content of superoxide anion radical, malondialdehyde and the antioxidant enzyme activities of CAT, APX, POD and PPO increased significantly, At the same time, the content of total phenols and flavonoids were increased under transport vibration stress, but the ability of DPPH and ABTS free radical scavenging of sweet cherry were reduced significantly. In particular, transportation vibration stress had a greater impact on the nutritional quality and antioxidant activity of "Nanyang", a sweet cherry with poor storage resistance. The results of this study indicated that transportation vibration has a great impact on the nutritional quality of sweet cherry, and that there is a strong correlation between antioxidant activity and nutritional quality. This study confirmed that transportation vibration during cold chain transportation can significantly reduce the nutritional quality and antioxidant activity of sweet cherry.
\end{abstract}

Keywords: sweet cherry; simulate transport vibration; nutritional quality; antioxidant activity; principal component analysis.

Practical Application: Though simulate transport and storage of sweet cherry, used principal component analysis to analyze the relationship between the nutritional quality and antioxidant activity. Provide a theoretical basis for the storage and preservation technologies, the cultivation of new varieties, and the exploration of softening mechanism of sweet cherries.

\section{Introduction}

Sweet cherry, which peel is thin, is rich in nutrition, and the flesh is soft and juicy. In recent years, sweet cherry has been welcomed by consumers because of its unique taste and strong antioxidant function (Gao et al., 2017). Sweet cherry is suitable for growing in tropical and subtropical areas with abundant rain, sunny and suitable temperature (Tokatlı \& Demirdöven, 2020). In order to eliminate the regional limitation of sweet cherry and improve its commercial value, cold chain transportation and storage has become an inevitable development trend (Alique et al., 2005).

In the whole cold chain process, transportation and storage, interacting parts between the fruit and the box or fruits will be subjected to various pressures, such as squeezing, friction, collision and impact (Wei et al., 2019). When the relative strength of these forces that damage the fruit is relatively high, the fruit will be damaged by the shallow surface, and due to the repeated action of the external force, the connection force between the fruit cells and the strength between the cells will change, resulting in brittleness or plasticity of the fruit injury makes the fruit soft (Wei et al., 2019; Zhou \& Wu, 2018). Directly damages the plasma membrane of the damaged area, softens it and reduces its oxidation resistance (Cliff \& Toivonen, 2017).

At present, a lot of research has been carried out on post-harvest storage and preservation technologies of sweet cherry, such as modified atmosphere preservation method
(Cozzolino et al., 2019), preservation of fungicides, chemical preservation method (Ni, 2018; Yang, 2009; Ma et al., 2019a), and physical preservation method (Michailidis et al., 2019; Tian et al., 2019). However, there are relatively few studies on the effect of different circulation and packaging conditions on fruit quality during transport.

The red cherry "Summit" has small epidermal cells, dense arrangement, thick surface wax and cell walls, and uniform internal cell size, so has good storage and transportation characteristics. The yellow cherry "Nanyang" has a loose epidermis and internal cell arrangement, and the surface layer is not waxy, which is extremely resistant to transportation. In this paper, "Summit" and "Nanyang" were used as experimental samples, studied the effect of transport vibration on the nutritional quality and antioxidant activity of sweet cherry fruit during cold chain transportation. The results will provide a reference for the development of post-harvest long-distance logistics transportation and storage technology development.

\section{Materials and methods}

\subsection{Sample preparation and treatments}

The test sweet cherries were picked from orchards in Dalian, Liaoning Province, China. Then they were quickly transported to the laboratory. Sweet cherries with a uniform size $(6 \pm 2 \mathrm{~g})$ 
and no obvious mechanical damage was selected as the test sample. Samples of each variety were randomly divided into two groups for processing. Each group was treated as follows: (1) Control group processing: $0 \mathrm{~h}$ treatments were used as the control group; (2) Vibration group processing: two layers of paper towels were glued on the bottom and around the incubator. Sweet cherries were put into the incubator gently, and the surface was covered with two layers of paper towels. The sealed insulation box was put into a constant temperature culture oscillator to simulate the mechanical vibration during road transportation. The conditions were set by the constant temperature culture oscillator: vibration frequency $(120 \mathrm{r} / \mathrm{min})$, temperature $\left(4^{\circ} \mathrm{C}\right)$, relative humidity $(90-95 \%)$ and time $(4 \mathrm{~h})$. To simplify recording, the "Summit" control and vibration treatment were referred as S-CK and S-V; the "Nanyang" control and vibration treatment were referred as $\mathrm{N}-\mathrm{CK}$ and $\mathrm{N}-\mathrm{V}$.

\subsection{Determination of soluble solids content, titratable acid and vitamin $C$}

The content of soluble solids (SSC) was determined according to the method described by NY/ T2637-2014 (China, 2014). Titratable acid (TA) and vitamin C (VC) were determined by Hernández-Muñoz et al. (2008).

\subsection{Determination of total phenol content and flavonoids}

The total phenol content (TPC) was determined by the Folinphenol colorimetric method (Rodov et al., 2010). Flavonoids content was determined by aluminum nitrate colorimetric method (Jiao et al., 2017).

\subsection{Determination of the antioxidant enzyme activities}

Determination of polyphenol oxidase

The activity of sweet cherry polyphenol oxidase (PPO) was extracted according to the method described by Cao et al. (2007) with slight modifications. Crude enzyme extract $(100 \mu \mathrm{L})$ was incubated with a buffered substrate $(1.0 \mathrm{~mL} 50 \mathrm{mmol} / \mathrm{L}$ catechol in $4 \mathrm{~mL}$ sodium phosphate buffer $\mathrm{pH} 7.8$ ), and monitored by measuring the increase in absorbance at $398 \mathrm{~nm}$.

\section{Determination of peroxidase}

The activity of cherry peroxidase (POD) was determined by Cao et al. (2007).

\section{Determination of catalase}

Catalase (CAT) was extracted according to the method described by Pasquariello et al. (2015) with slight modifications. The reaction solution contained $0.2 \mathrm{~mL}$ enzyme solution, $1.5 \mathrm{~mL}$ $50 \mathrm{mmol} / \mathrm{L}$ phosphate buffers $(\mathrm{pH} 7.8$ ) and $0.3 \mathrm{~mL} 10 \mathrm{mmol} / \mathrm{L}$ $\mathrm{H}_{2} \mathrm{O}_{2}$ the time was counted immediately and the absorbance was measured at $240 \mathrm{~nm}$.

\section{Determination of ascorbate peroxidase}

The activity of ascorbate peroxidase (APX) was determined according to the previously published method (Cao et al., 2007).

\subsection{Determination of superoxide anion}

The content of superoxide anion radical $\left(\mathrm{O}_{2}^{-}\right)$was modified according to the previously published method (Zhao et al., 2008).

\subsection{Determination of malondialdehyde content}

Malondialdehyde content (MDA) was determined by Pasquariello et al. (2015).

\subsection{Determination of antioxidant capacity}

\section{Determination of DPPH free radical scavenging rate}

The DPPH free radical scavenging rate (DPPH) was determined according to the method of Chavan et al. (2013) with slight modifications. The reaction solution contained supernatant $(0.2 \mathrm{~mL})$ and DPPH solution $(2.8 \mathrm{~mL})$. Thoroughly mix, and leave the water bath at $37^{\circ} \mathrm{C}$ for 30 minutes, and then determination of absorbance at $517 \mathrm{~nm}$, which was referred to as $\mathrm{A}_{\mathrm{i}}$. At the same time, the absorbance $\mathrm{A}_{0}$ of DPPH solution mixed with anhydrous ethanol $(1: 1)$ and the absorbance $\mathrm{A}_{j}$ of mixed supernatant solution and anhydrous ethanol (1:1) were determined (Equation 1).

$D P P H$ free radical scavenging rate $(\%)=\left[1-\left(A_{i}-A_{j}\right) / A_{0}\right] \times 100$ (1)

Determination of agreement of basic telecommunications services

The Agreement of Basic Telecommunications Services $\left(\mathrm{ABTS}^{+}\right)$free radical scavenging rate was determined according to the method of Zhang et al. (2019).

\subsection{Statistical analysis}

Analyses of data were carried out by one-way ANOVA in SPSS 19.0 for Windows (SPSS Inc., Chicago, IL, USA). Statistic differences were considered to be significant at $\mathrm{p}<0.05$. All results were expressed as the mean \pm SE. Difference significance among treatments was analyzed by Duncan's multiple range test.

\section{Results and discussion}

\subsection{Effect of the nutritional quality by simulated transport vibration in sweet cherry}

SSC, TA and VC

SSC was an important nutritional indicator of fruits and had a strong relationship with the acceptability of consumers, reflecting the sugar, acid, vitamins, minerals and other nutrients in the fruits (Cliff \& Toivonen, 2017). As shown in Table 1, SSC first increased slowly and then decreased during the storage and transportation period. The content of SSC in the vibration treatment group of "Summit" or "Nanyang" was lower than 


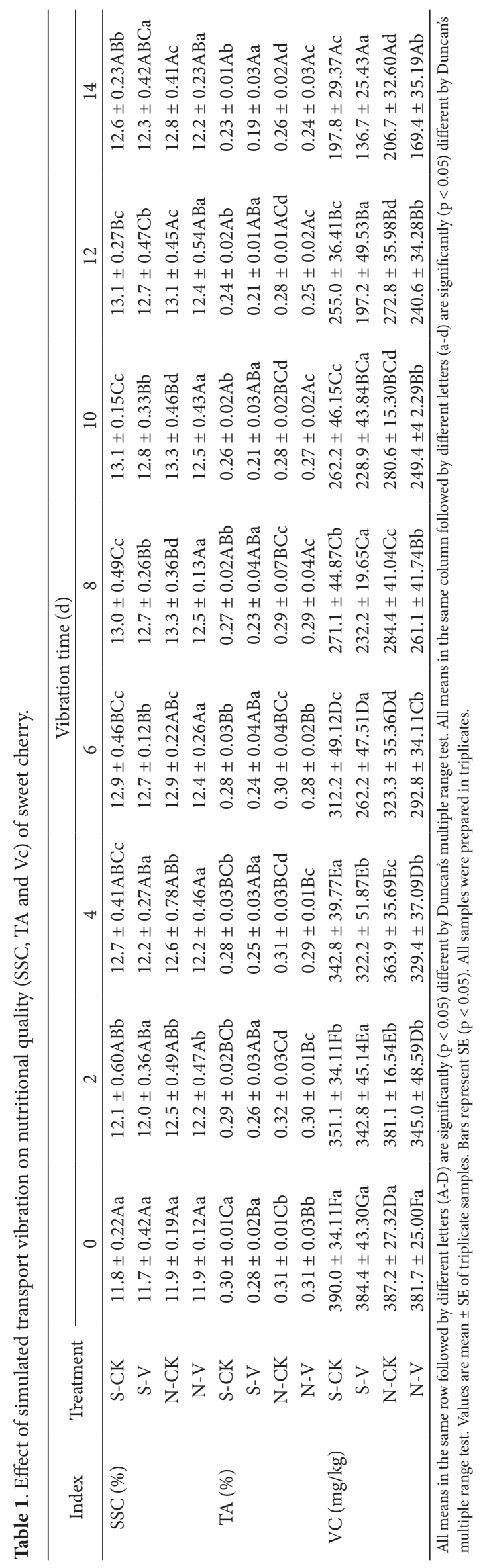


that in the control treatment groups. The vibration treatment group reached the maximum value on the 10th day, while the control treatment group on the 12th day. At the 14th day, SSC of the S-V and N-V were $2.44 \%$ and $4.92 \%$ lower than that of $\mathrm{S}-\mathrm{CK}$ and N-CK respectively. SSC included soluble proteins and soluble sugars. During storage period, basic physiological activities were maintained and the substances such as soluble solids were accumulated. However, with the ripening and aging of sweet cherry, the fruit itself cannot make up for consumption, so the soluble solid content gradually decreased.

TA is also an important part of the quality of the fruits (Yang, 2009). The organic acid content has an important influence on the taste, flavor, sugar-acid ratio and $\mathrm{pH}$ of fruits (Fan et al., 2014). As shown in Table 1, TA content of sweet cherry in each treatment group showed a downward trend. Whether it was "Summit" or "Nanyang", the TA content of the vibration treatment group was always lower than that of the control treatment group. At the 14th day, the decline trend of the S-V was the most obvious, with a decline of $32.14 \%$. From this, it could be seen that the simulated transport vibration treatment promoted the consumption of the TA content of the sweet cherry.

$\mathrm{VC}$ is an important nutrients component, but it is easily decomposed during storage. The change of $\mathrm{VC}$ content reflects the freshness of fruits, and it is also one of the indicators for judging the freshness preservation effect (Xu et al., 2017). As shown in Table 1, the VC content of all treatment groups gradually decreased. The simulated transport vibration treatment accelerated the decomposition of VC in sweet cherry, and the $\mathrm{VC}$ content of the S-V decreased more rapidly than the N-V. At the 14th day, the decline rates of S-CK, S-V, N-CK and N-V were $48.55 \%, 64.96 \%, 45.85 \%$ and $56.24 \%$, respectively.

\section{TPC and flavonoids content}

After mechanical damage, fruits often produce a series of secondary metabolites, such as phenols, flavonoids, and alkaloids. These substances are mainly concentrated in the wound and its adjacent parts, and participate in the formation of callus and resist the invasion of insects or germ (Ma et al., 2018). As shown in Figure 1a, TPC of each treatment group increased first and then decreased, and the content of the vibration treatment group was significantly higher than that of the control treatment group. In the early storage period, the TPC of S-V was at a relatively high level, and in the later storage period, the total phenol content of $\mathrm{N}-\mathrm{V}$ was significantly higher than that of other treatment groups. On the 14th day, the total phenol contents of S-CK, S-V, $\mathrm{N}-\mathrm{CK}$ and $\mathrm{N}-\mathrm{V}$ were $1.45,1.75,1.50$ and $2.08, \mathrm{U}$, respectively. This indicated that simulated transport vibration accelerated the TPC of sweet cherries.

As shown in Figure 1b, the flavonoids content of sweet cherry in each treatment group first increased and then decreased, and its peak value appeared on the 8th day of storage. The peak values of S-CK, S-V, N-CK, and N-V were $30.08,36.59,39.32$ and $42.38, \mathrm{mg} / \mathrm{g}$, respectively. On the 14 th day, the flavonoid content of S-V was $18.39 \%$ higher than that of S-CK, and the flavonoid content of $\mathrm{N}-\mathrm{V}$ was $3.59 \%$ higher than that of N-CK. The results indicated that simulated transport vibration increased the secondary metabolites of sweet cherry. The increase of secondary metabolites is also a stress response of fruits to injury stress, and a self-protection effect of fruits against adversity.

\subsection{Effect of the active oxygen metabolism by simulated transport vibration in sweet cherry}

\section{$P P O$ and $P O D$}

PPO is a copper-based enzyme that exists in the free form of plant cytoplasm or bounds to mitochondria, chloroplasts and other subcellular organelles (Ma et al., 2019a). It catalyzes the reaction of various phenols with $\mathrm{O}_{2}$ to form hydrazine, which is also a major part of terminal oxidase. PPO is a key enzyme that promotes enzymatic browning of fruits. As shown in Table 2, the PPO activity of sweet cherry showed an upward trend. On the 12th day, the PPO activity of each treatment group increased significantly. The activity of the $\mathrm{S}-\mathrm{V}$ and $\mathrm{N}-\mathrm{V}$ were higher than that of the corresponding control treatment group. Among them, the activity of the S-V was always at the highest level.

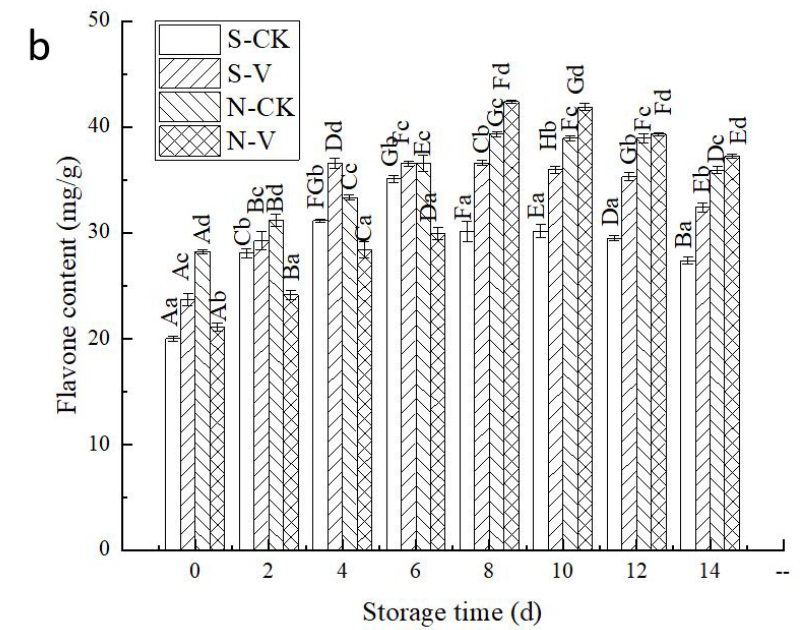

Figure 1. Effect of simulated transports vibration on TPC (a) and flavonoids (b) of sweet cherry. Bars represent SE ( $p<0.05)$. All samples were prepared in triplicates. 


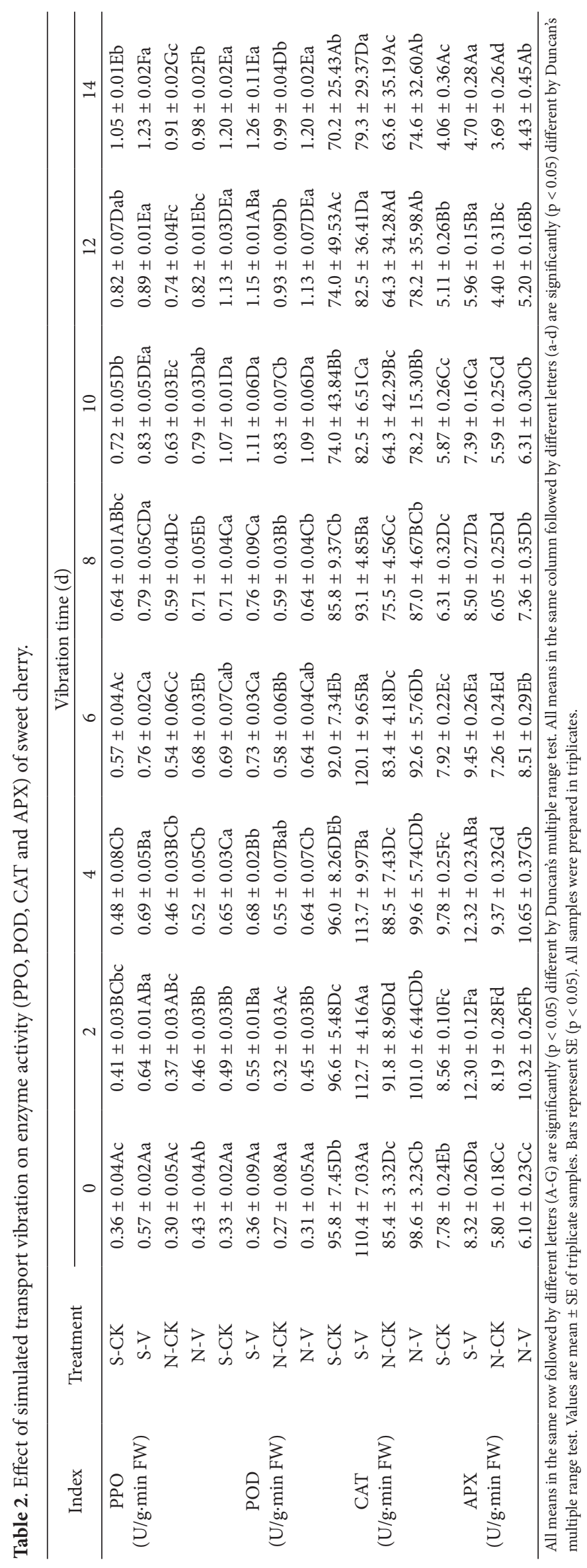


This indicates that simulated transport vibration significantly increased the PPO activity of sweet cherry. Moreover, compared with "Nanyang", the simulate transport vibration treatment made the PPO activity of the "Summit" easier to rise. Studies showed that PPO activity could increase significantly when plant tissue was susceptible or causes damage under other adverse conditions, and it played a protective role.

POD is one of the important enzymes in the active oxygen free radical scavenging system (Ma et al., 2019a). It plays a role in the decomposition of $\mathrm{H}_{2} \mathrm{O}_{2}$ in the last step of lignin biosynthesis and has a certain effect on the color change of fruits. The increase of POD activity is an important sign of the ripening and aging of fruit tissues (Chen et al., 2019). POD can be activated by $\mathrm{H}_{2} \mathrm{O}_{2}$, which triggers a series of toxic effects on tissues. The mechanism is that POD degrades the indoleacetic acid in fruit tissues by catalytic oxidation (Zhong $\&$ Zhu, 2004). As shown in Table 2 , the POD activity showed an increasing trend. At 8 days after storage, the POD activity of each treatment group changed slowly, and the activity of POD increased rapidly on the 10th day. And during the whole storage period, the POD activity of $\mathrm{S}-\mathrm{V}$ and $\mathrm{N}-\mathrm{V}$ were always higher than the corresponding control treatment group. It indicated that simulated transport vibration promotes an increase in POD activity of sweet cherry.

\section{CAT and APX}

CAT is a protective enzyme in the ripening and aging process of fruits, and one of the key enzymes in the biological defense system. It can decompose $\mathrm{H}_{2} \mathrm{O}_{2}$ into oxygen and water, remove $\mathrm{H}_{2} \mathrm{O}_{2}$ and prevent cells from being poisoned by $\mathrm{H}_{2} \mathrm{O}_{2}$, so as to reduce damage to the membrane and achieve the purpose of delaying cell senescence (Wang et al., 2018). As shown in Table 2, the CAT activity of each treatment group showed a slow increase first, and reached the highest on the 6th day, then decreased rapidly. This may be due to the accumulation of $\mathrm{H}_{2} \mathrm{O}_{2}$ during the early storage period of sweet cherries, which induced the increase of CAT enzyme activity. When the accumulated amount is not cleaned in time, it is possible to inhibit the CAT enzyme activity. Meanwhile, The CAT activity of S-V and $\mathrm{N}-\mathrm{V}$ were always higher than $\mathrm{S}-\mathrm{CK}$ and $\mathrm{N}-\mathrm{CK}$, respectively. It indicated that simulated transportation vibration promoted the expression of CAT activity of sweet cherry.

APX is a highly specific peroxidase that exists in the fruit. It can catalyze the oxidation-reduction reaction of ascorbic acid with $\mathrm{H}_{2} \mathrm{O}_{2}$ to achieve the purpose of removing $\mathrm{H}_{2} \mathrm{O}_{2}$ and thus limit the reaction between $\mathrm{O}_{2}{ }^{-}$and $\mathrm{H}_{2} \mathrm{O}_{2}$ to produce peroxides such as .OH (Liu et al., 2017). As shown in Table 2, the APX activity increased first and then decreased. The content of each treatment group reached the maximum value on the 4th day of storage. The APX activity of the S-CK, S-V, N-CK and N-V were 12.80, 9.78, 10.60 and 9.40, U/g.min FW. The activity levels of S-V and the $\mathrm{N}-\mathrm{V}$ were lower than the corresponding control treatment group, and the activity of S-CK was always at the highest level, while the activity of $\mathrm{N}-\mathrm{V}$ was always at the lowest level.

\section{$3.3 \mathrm{O}_{2}^{-}$production rate}

During the storage and transportation of fruits, the intracellular free radical metabolism balance is often disrupted, accumulating a large amount of free radicals and triggering or aggravating lipid peroxidation, resulting in the loss of the cell plasma membrane system. Free radicals are atoms or groups of atoms with unpaired valence electrons. Oxygen molecules that enter the body through respiration receive only one electron and are converted into $\mathrm{O}_{2} \cdot \mathrm{O}_{2}{ }^{-}$acts with other oxygen free radicals on biofilms, attacks membrane proteins, and causes the unsaturated fatty acids on the membrane undergo peroxidation, which destroys the membrane system (Nan et al., 2017).

As shown in Table 3, the $\mathrm{O}_{2}$ tended to rise as a whole. At the beginning of storage, the content of $\mathrm{O}_{2}^{-}$in each treatment group increased slowly. From the 6th day, the content of $\mathrm{O}_{2}{ }^{-}$increased rapidly. The content of $\mathrm{O}_{2}^{-}$in vibration treatment groups were always higher than that in control treatment groups, and the increase of $\mathrm{N}-\mathrm{V}$ was the most obvious. This indicates that simulated transport vibration increased the rise of $\mathrm{O}_{2}^{-}$of sweet cherry.

\subsection{MDA content}

Lipids exist on the cell membrane, which are related to the stress resistance of the fruit during storage. During the storage process, with the content of fatty acids decreases, the peroxidation of internal membrane lipids and the increase of active oxygen and free radicals will destroy the structure and function of the membrane, thereby destroying the structure of the cell membrane, enhancing permeability and graduality oxidation and aging of fruits (Nan et al., 2017). MDA is an important product of membrane peroxidation, which can directly produce toxic effects on cells, caused cross-linking and inactivation of enzyme proteins in biofilms, lead to membrane pores and enhance permeability. MDA can be used as membrane quality index of peroxidation.

With the extension of storage time, MDA content of sweet cherry increased gradually. At the same time, MDA contents of simulated transportation vibration treatments S-V and N-V were higher than their control treatments, and MDA content of $\mathrm{N}-\mathrm{V}$ was always at the highest level during the later stage of storage (Table 3). It showed that simulated transportation vibration increased the degree of peroxidation of sweet cherry membrane lipids.

\subsection{Effect of the antioxidant capacity by simulated transport vibration in sweet cherry.}

According to the DPPH and $\mathrm{ABTS}^{+}$methods which determine the antioxidant capacity, the higher clearance value indicated higher antioxidant capacity (Ma et al., 2019b; Pasquariello et al., 2015). As shown in Table 3 , their antioxidant capacity decreased generally, and the antioxidant capacities of S- $\mathrm{V}$ and $\mathrm{N}-\mathrm{V}$ treatment were lower than that of its control treatment, respectively. In the early storage period, the antioxidant capacity of "Summit" was always higher than that of "Nanyang". In the later stage, the result is just the opposite. 


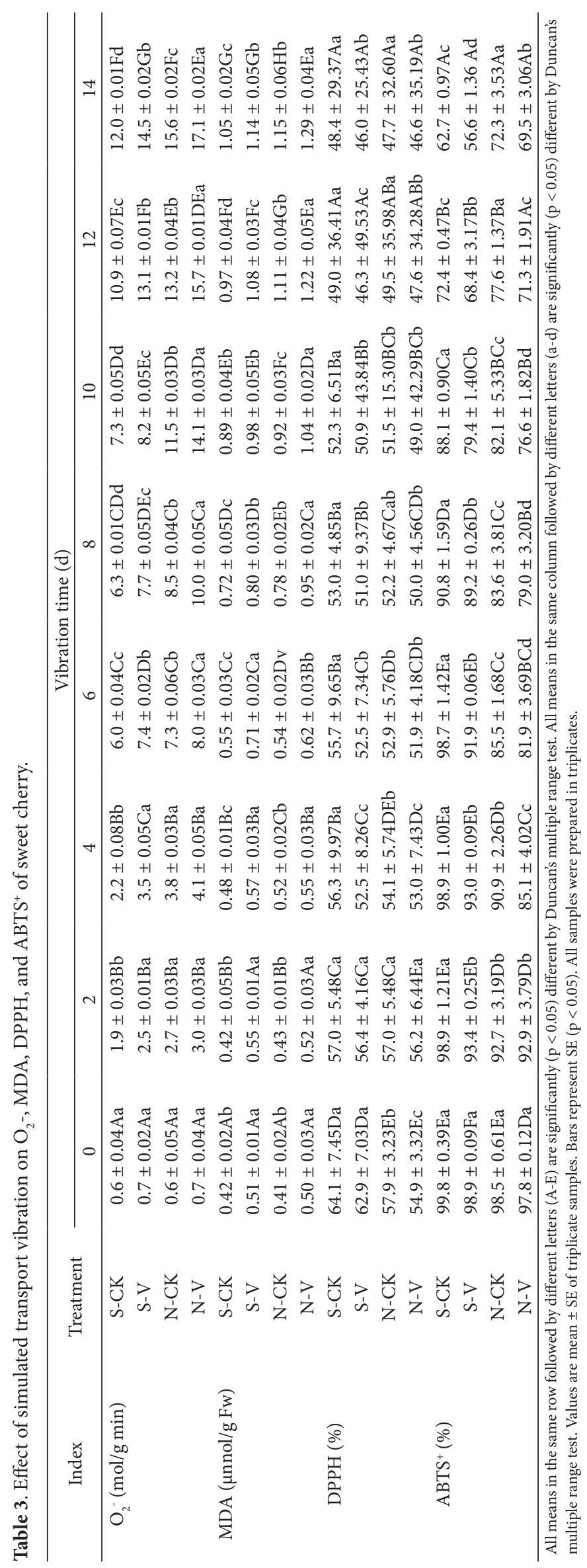




\subsection{Correlation ability}

In order to determine the effects of antioxidant components and simulated transportation vibration on the antioxidant capacity of sweet cherry, the correlation of between antioxidant indexes and antioxidant capacity were analyzed (see Figure 2). $\mathrm{DPPH}$ free radical scavenging ability was positively related to TA, flavonoids, PPO, POD, CAT and APX, but negatively correlated with $\mathrm{O}_{2}^{-}, \mathrm{MDA}$ and TPC. $\mathrm{ABTS}^{+}$free radical scavenging ability was positively correlated with TA, VC, flavonoids and $\mathrm{O}_{2}$ - and MDA.

The correlation results of 13 indicators showed that TA, VC, TPC, flavonoids, PPO, POD, CAT, APX, $\mathrm{O}_{2}{ }^{-}$and MDA of sweet cherry were important antioxidants. They can directly affect the antioxidant capacity of sweet cherry. The antioxidant capacity of vibration groups was become weaker, which may be due to their lower retention of antioxidant components.

\subsection{Principal component analysis}

The principal component analysis (PCA) showed that the cumulative variance contribution rate of the first three principal components reached $88.97 \%$ (see Table 4), which indicated that these three principal components could accurately and objectively reflect the similarity between samples, so a total of three principal components were extracted (Nascimento et al. 2020; Fernandes et al.. 2019).

The first main component included TPC, PPO, POD, CAT, APX, and $\mathrm{O}_{2}{ }^{-}$and MDA. Among them, PPO, POD, CAT, and

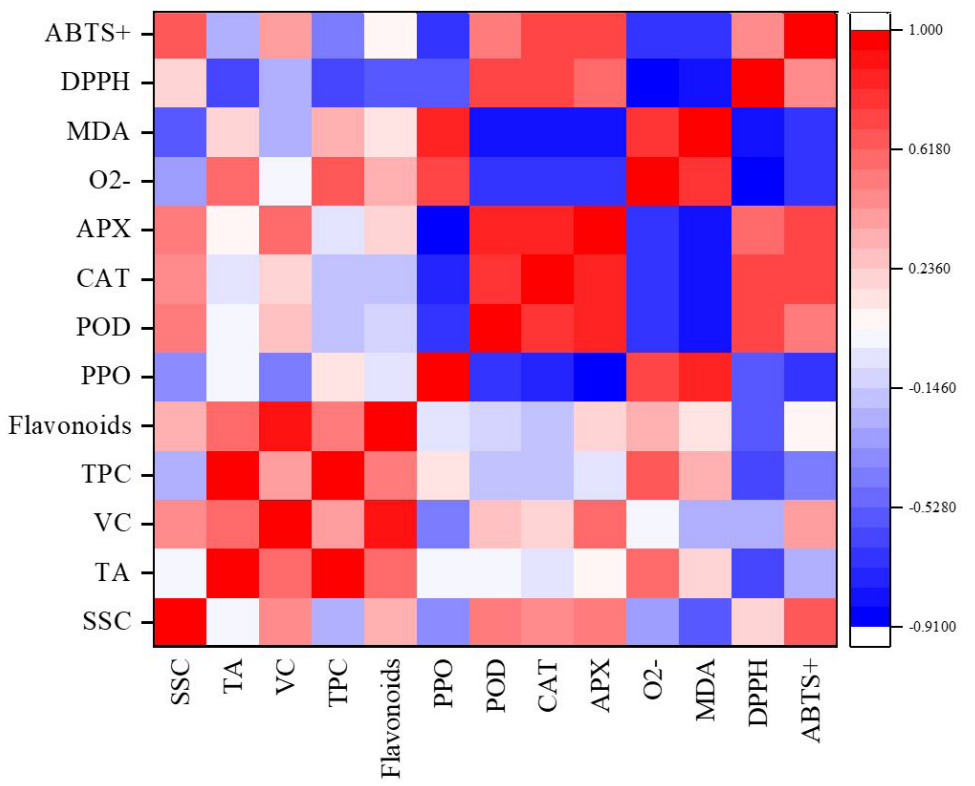

Figure 2. Correlation Analysis of the measured parameters of sweet cherry.

Table 4. Explain the total variance of principal components

\begin{tabular}{|c|c|c|c|c|c|c|}
\hline \multirow[b]{2}{*}{ Ingredient } & \multicolumn{3}{|c|}{ Initial eigenvalue } & \multicolumn{3}{|c|}{ Rotational square sum loading } \\
\hline & Total & $\begin{array}{c}\text { Variance } \\
\text { contribution rate } \%\end{array}$ & $\begin{array}{c}\text { Cumulative variance } \\
\text { contribution } \%\end{array}$ & Total & $\begin{array}{c}\text { Variance } \\
\text { contribution rate } \%\end{array}$ & $\begin{array}{c}\text { Cumulative variance } \\
\text { contribution } \%\end{array}$ \\
\hline 1 & 6.559 & 43.729 & 43.729 & 6.434 & 42.896 & 42.896 \\
\hline 2 & 5.365 & 35.766 & 79.496 & 5.254 & 35.027 & 77.923 \\
\hline 3 & 1.421 & 9.474 & 88.970 & 1.657 & 11.047 & 88.970 \\
\hline 4 & .596 & 3.973 & 92.943 & & & \\
\hline 5 & .379 & 2.527 & 95.470 & & & \\
\hline 6 & .232 & 1.544 & 97.014 & & & \\
\hline 7 & .206 & 1.373 & 98.387 & & & \\
\hline 8 & .154 & 1.026 & 99.413 & & & \\
\hline 9 & .055 & .366 & 99.779 & & & \\
\hline 10 & .022 & .147 & 99.926 & & & \\
\hline 11 & .011 & .074 & 100.000 & & & \\
\hline 12 & .000 & .000 & 100.000 & & & \\
\hline 13 & .000 & .000 & 100.000 & & & \\
\hline
\end{tabular}


APX were positively related to the first main component, while TPC, $\mathrm{O}_{2}^{-}$and MDA were negatively correlated with the first principal component. The second main component including $\mathrm{TA}, \mathrm{V}_{\mathrm{C}}$, flavonoids, and $\mathrm{ABTS}^{+}$free radical scavenging rate were all positively correlated with the second main component. The third main component including SSC and DPPH free radical scavenging rates were positively correlated with the third main component (see Table 5 and Table 6)

Table 5. Component Matrix of principal component analysis.

\begin{tabular}{cccc}
\hline \multirow{2}{*}{ Ingredient } & \multicolumn{3}{c}{ Component } \\
\cline { 2 - 4 } & 1 & 2 & 3 \\
\hline SSC & -.013 & .061 & .940 \\
TA & .220 & .963 & -.011 \\
VC & -.246 & .853 & .035 \\
TPC & -.940 & -.104 & -.107 \\
Flavonoids & -.164 & .910 & .321 \\
PPO & .878 & .235 & .209 \\
POD & .959 & -.007 & -.161 \\
CAT & .883 & .024 & .134 \\
APX & .951 & .140 & .125 \\
O2- & -.864 & .286 & .082 \\
MDA & -9.37 & .284 & -.017 \\
DPPH & .521 & .266 & .625 \\
ABTS+ & -.189 & .933 & .118 \\
\hline
\end{tabular}

Table 6. Component load matrix of principal component analysis

\begin{tabular}{cccc}
\hline \multirow{2}{*}{ Ingredient } & \multicolumn{3}{c}{ composition } \\
\cline { 2 - 4 } & 1 & 2 & 3 \\
\hline SSC & -.013 & .061 & .940 \\
TA & .220 & .963 & -.011 \\
VC & -.246 & .853 & .035 \\
TPC & -.940 & -.104 & -.107 \\
Flavonoids & -.164 & .910 & .321 \\
PPO & .878 & .235 & .209 \\
POD & .959 & -.007 & -.161 \\
CAT & .883 & .024 & .134 \\
APX & .951 & .140 & .125 \\
O2- & -.864 & .286 & .082 \\
MDA & -9.37 & .284 & -.017 \\
DPPH & .521 & .266 & .625 \\
ABTS + & -.189 & .933 & .118 \\
\hline
\end{tabular}

\subsection{PCA analysis of shelf quality of sweet cherries with different treatments}

According to the results of PCA, the contribution rate of the first, second and third principal component was $42.896 \%$, $35.027 \%$ and $11.047 \%$, respectively (Table 4 ), and the cumulative contribution rate was $88.970 \%$. Three principal components were used to evaluate the different treatments of sweet cherry, and the comprehensive score (F) was calculated (Equation 2).

$F=\left(42.896 \% * F_{1}+35.027 \% * F_{2}+11.047 \% * F_{3}\right) / 88.970 \%$

where: $F_{1}, F_{2}, F_{3}$ and $F$ were the score of the first, second, third principal component and a comprehensive score. The higher the F score, the better the quality (Ma et al., 2018).

As shown in Table 7, the F of each group showed a downward trend with the prolongation of storage time. After 14 days storage, the comprehensive score relationship of each group was: $\mathrm{S}-\mathrm{CK}>$ $\mathrm{N}-\mathrm{CK}>\mathrm{S}-\mathrm{V}>\mathrm{N}-\mathrm{V}$. This showed that the simulated transport vibration accelerated the quality degradation of sweet cherry during simulated transport storage. Meanwhile, transportation vibration stress had a greater impact on the nutritional quality and antioxidant activity of "Nanyang", a sweet cherry with poor storage resistance.

\section{Conclusions}

Transport vibration often leads to the damage of fruit surface tissue and physiological abnormalities inside the fruit, thus accelerating the softening and aging of fruit. Among them, apparent damage of the fruit which is visible to the naked eye is easy to find and deal with in time. The damage of internal tissue caused by transportation vibration is most easily overlooked and the damage of fruit is more serious. The results of this study indicated that transportation vibration has a great impact on the nutritional quality of sweet cherry, and that there is a strong correlation between antioxidant activity and nutritional quality. In order to maintain the original quality of the sweet cherry fruit, the logistics time should be shorten, and it is necessary that vibration reduction packaging measures should be taken to reduce the damage of vibration to the fruit.

\section{Acknowledgements}

This work was supported by “Thirteenth Five-Year” National Key R\&D Program "Research and Demonstration of Key Technology in Characteristic Juice Processing”, 2017YFD0400704-4.

Table 7. Comprehensive quality change of sweet cherry in simulated transportation.

\begin{tabular}{|c|c|c|c|c|c|c|c|c|}
\hline \multirow{2}{*}{ Treatment } & \multicolumn{8}{|c|}{ Storage time $(\mathrm{d})$} \\
\hline & 0 & 2 & 4 & 6 & 8 & 10 & 12 & 14 \\
\hline S-CK & $1.18 \pm 0.08 \mathrm{Ha}$ & $1.03 \pm 0.09 \mathrm{Ga}$ & $0.98 \pm 0.05 \mathrm{Fa}$ & $0.85 \pm 0.09 \mathrm{Ea}$ & $0.67 \pm 0.07 \mathrm{Da}$ & $0.23 \pm 0.05 \mathrm{Ca}$ & $-0.01 \pm 0.09 \mathrm{Ba}$ & $-0.15 \pm 0.08 \mathrm{Aa}$ \\
\hline $\mathrm{S}-\mathrm{V}$ & $1.09 \pm 0.09 \mathrm{Ha}$ & $0.95 \pm 0.08 \mathrm{~Gb}$ & $0.88 \pm 0.08 \mathrm{Fc}$ & $0.62 \pm 0.05 \mathrm{Ec}$ & $0.43 \pm 0.09 \mathrm{Dc}$ & $0.15 \pm 0.08 \mathrm{Cb}$ & $-0.12 \pm 0.06 \mathrm{Bc}$ & $-0.24 \pm 0.09 \mathrm{Ac}$ \\
\hline $\mathrm{N}-\mathrm{CK}$ & $1.12 \pm 0.03 \mathrm{Hb}$ & $1.01 \pm 0.02 \mathrm{Ga}$ & $0.92 \pm 0.06 \mathrm{Fb}$ & $0.81 \pm 0.06 \mathrm{~Eb}$ & $0.59 \pm 0.06 \mathrm{Db}$ & $0.21 \pm 0.07 \mathrm{Ca}$ & $-0.06 \pm 0.07 \mathrm{Bb}$ & $-0.18 \pm 0.05 \mathrm{Ab}$ \\
\hline $\mathrm{N}-\mathrm{V}$ & $1.01 \pm 0.08 \mathrm{Hb}$ & $0.89 \pm 0.06 \mathrm{Gc}$ & $0.76 \pm 0.04 \mathrm{Fd}$ & $0.59 \pm 0.09 \mathrm{Ed}$ & $0.38 \pm 0.07 \mathrm{Dd}$ & $0.11 \pm 0.06 \mathrm{Cc}$ & $-0.15 \pm 0.08 \mathrm{Bd}$ & $-0.31 \pm 0.08 \mathrm{Ad}$ \\
\hline
\end{tabular}

All means in the same row followed by different letters $(\mathrm{A}-\mathrm{H})$ are significantly $(\mathrm{p}<0.05)$ different by Duncan's multiple range test. All means in the same column followed by different letters $(\mathrm{a}-\mathrm{d})$ are significantly $(\mathrm{p}<0.05)$ different by Duncan's multiple range test. Values are mean \pm SE of triplicate samples. Bars represent SE ( $\mathrm{p}<0.05)$. All samples were prepared in triplicates. 


\section{References}

Alique, R., Zamorano, J. P., Martínez, M. A., \& Alonso, J. (2005). Effect of heat and cold treatments on respiratory metabolism and shelf-life of sweet cherry, type picota cv "Ambrunés". Postharvest Biology and Technology, 35(2), 153-165. http://dx.doi.org/10.1016/j.postharvbio.2004.07.003.

Cao, J. K., Jiang, W. B., \& Zhao, Y. M. (2007). Guidance on post-harvest physiological and biochemical experiments offruits and vegetables. Beijing: China Light Industry Press.

Chavan, J. J., Jagtap, U. B., Gaikwad, N. B., Dixit, G. B., \& Bapat, V. A. (2013). Total phenolics, flavonoids and antioxidant activity of Saptarangi (Salacia chinensis L.) fruit pulp. Plant Biochem Biotechno, 22(4), 409-413. http:// dx.doi.org/10.1007/s13562-012-0169-3.

Chen, Y., Liu, C. H., Bai, W. R., Fu, X. Q., \& Gao, F. (2019). Study on the preservation of fresh-cut apples by chitosan. Science and Technology of Food Industry, 40, 269-274.

China. (2014). NY/T2637-2014: determination of soluble solids content in fruits and vegetables. Beijing: China Standard Publication.

Cliff, M. A., \& Toivonen, P. M. A. (2017). Sensory and quality characteristics of 'Ambrosia' apples in relation to harvest maturity for fruit stored up to eight months. Postharvest Biology and Technology, 132, 145-153. http:// dx.doi.org/10.1016/j.postharvbio.2017.05.015.

Cozzolino, R., Martignetti, A., Cefola, M., Pace, B., Capotorto, I., De Giulio, B., Montemurro, N., \& Pellicano, M. P. (2019). Volatile metabolites, quality and sensory parameters of "Ferrovia" sweet cherry cold stored in air or packed in high CO2 modified atmospheres. Food Chemistry, 286, 659668. http://dx.doi.org/10.1016/j.foodchem.2019.02.022. PMid:30827661.

Fan, L. L., Li, M. M., Feng, X. Q., Han, P. X., Duan, X. M., \& Zhang, B. (2014). Effect of chitosan coating on storage quality of Fresh-cut Apples. Shipin Kexue, 35, 350-355.

Fernandes, M., Moraes, S. M., Sousa, P. H., Magalhães, C. E., Almeida, M. M., \& Silva, M. G. (2019). Characterization of leaves used in infusion preparation grown in northeastern Brazil by chemometric methods based on their multi-elemental composition. Food Science and Technology, 39(Suppl. 1), 309-315. http://dx.doi.org/10.1590/fst.00718.

Gao, F., Xia, H., Wang, X., Wang, J., Zhou, Q., Lv, X. L., \& Liang, D. (2017). Analysis of antioxidant substances and antioxidant activities in different sweet cherry varieties. Journal of Zhejiang Agricultural Sciences, 29, 926-932.

Hernández-Muñoz, P., Almenar, E., Valle, V. D., Velez, D., \& Gavara, R. (2008). Effect of chitosan coating combined with postharvest calcium treatment on strawberry (Fragaria $\times$ ananassa) quality during refrigerated storage. Food Chemistry, 110(2), 428-435. http://dx.doi.org/10.1016/j. foodchem.2008.02.020. PMid:26049236.

Jiao, Z. G., Liu, J. C., Liu, H., Zhang, C. L., Wang, S. X., \& Yang, G. M. (2017). Effects of short-wave ultraviolet irradiation on nutritional quality and antioxidant activity of postharvest sweet cherry fruits. Journal of Chinese Institute of Food Science and Technology, 17(1), 170-178.

Liu, H., Liang, S., Li, Q. L., Bai, Y., Yan, Y. T., \& Guo, J. L. (2017). Effects of postharvest $\mathrm{H}_{2} \mathrm{O}_{2}$ and tea polyphenol treatments on active oxygen metabolism and senescence of strawberry fruits. Journal of Yunnan Agricultural University, 32, 504-509.

Ma, C., Cao, S., Long, X. B., Jin, N., Yang, X. Z., Ma, K. Z., Ma, L. Z., \& Wang, R. (2018). Evaluation of fresh transportation and shelf quality of blueberries with different treatments based on principal component analysis. Food Science and Technology, 43, 30-37.

Ma, Y. R., Ban, Q. F., Shi, J. Y., Dong, T. T., Jiang, C. Z., \& Wang, Q. G. (2019a). 1-Methylcyclopropene (1-MCP), storage time, and shelf life and temperature affect phenolic compounds and antioxidant activity of 'Jonagold' apple. Postharvest Biology and Technology, 150, 71-79. http:// dx.doi.org/10.1016/j.postharvbio.2018.12.015.

Ma, Y. Y., Fu, L., Hussain, Z., Huang, D. D., \& Zhu, S. H. (2019b). Enhancement of storability and antioxidant systems of sweet cherry fruit by nitric oxide- releasing chitosan nanoparticles (GSNO-CSNPs). Food Chemistry, 285, 10-21.http://dx.doi.org/10.1016/j.foodchem.2019.01.156. PMid:30797323.

Michailidis, M., Karagiannis, E., Polychroniadou, C., Tanou, G., Karamanoli, K., \& Molassiotis, A. (2019). Metabolic features underlying the response of sweet cherry fruit to postharvest UV-C irradiation. Plant Physiology and Biochemistry, 144, 49-57.http://dx.doi.org/10.1016/j.plaphy.2019.09.030. PMid:31557639.

Nan, H. F., Zhu, G. Y., Fan, L., Liu, Y., Liu, H., \& Guo, J. L. (2017). Changes of active oxygen and protective enzyme activities in strawberry fruit during dging. Beifang Yuanyi, 15, 123-126.

Nascimento, M. M., Jesus, R. M., Santos, H. M., Silva, A. L. S. Jr., Campos, N. M. C. O., Silva, E. G. P., \& Lôbo, I. P. (2020). Quality pattern evaluation of frozen soursop pulps: an assessment based on chemical composition and chemometric analysis. Food Science and Technology, 40(2), 508-516. http://dx.doi.org/10.1590/fst.04919.

$\mathrm{Ni}$, S. J. (2018). Study on the preservation and preservation of sweet cherries by different refrigeration and fresh-keeping treatments (Master degree thesis). Shandong Agricultural University, Taian.

Pasquariello, M. S., Di Patre, D., Mastrobuoni, F., Zampella, L., Scortichini, M., \& Petriccione, M. (2015). Influence of postharvest chitosan treatment on enzymatic browning and antioxidant enzyme activity in sweet cherry fruit. Postharvest Biology and Technology, 109, 45-56. http://dx.doi. org/10.1016/j.postharvbio.2015.06.007.

Rodov, V., Tietel, Z., Vinokur, Y., Horev, B., \& Eshel, D. (2010). Ultraviolet light stimulates FI avonol accumulation in peeled onions and controls microorganisms on their surface. Journal of Agricultural and Food Chemistry, 58(16), 9071-9076. http://dx.doi.org/10.1021/jf1016016. PMid:23654235.

Tian, Z. X., Long, M. X., Li, Y. F., He, Y. B., Liang, Q., \& Shi, B. (2019). Effects of short-wave ultraviolet irradiation and (60) Co- $\gamma$ irradiation treatment on storage quality of large cherries. Shipin Kexue, 40, 269-276.

Tokatl, K., \& Demirdöven, A. (2020). Effects of chitosan edible film coatings on the physicochemical and microbiological qualities of sweet cherry (Prunus avium L.). Scientia Horticulturae, 259, 108656. http://dx.doi. org/10.1016/j.scienta.2019.108656.

Wang, Y., Wang, Z. H., Wang, W. H., Tong, W., \& Song, L. (2018). Postharvest senescence and antioxidant enzymes of cherry fruits with different temperature and humidity Impact of activity. Storage and Process, 18, 1-6.

Wei, X. P., Xie, D. D., Mao, L. C., Xu, C. J., Luo, Z. S., Xia, M., Zhao, X. X., Han, X. Y., \& Lu, W. J. (2019). Excess water loss induced by simulated transport vibration in postharvest kiwifruit. Scientia Horticulturae, 250, 113-120. http://dx.doi.org/10.1016/j.scienta.2019.02.009.

Xu, S. X., Wu, H. Y., Chen, H. J., \& Han, Q. (2017). Effects of vibration stress on fruit quality and antioxidant enzyme activities of blueberry. Forestry Science, 53, 26-34.

Yang, Y. F. (2009). Research advances in postharvest physiology and storage and fresh keeping technology of big cherry. Beifang Yuanyi, 11, 122-124.

Zhang, H. F., Gao, Y. T., Na, J., Ma, J., \& Xiong, H. B. (2019). Study on the scavenging activity of 8 kinds of aquatic vegetables on water-soluble ABTS free radicals. Food Research and Development, 40, 8-13.

Zhao, L., He, J. X., Wang, X. M., \& Zhang, L. X. (2008). Nitric oxide protects against polyethylene glycol-induced oxidative damage in two ecotypes of reed suspension cultures. Journal of Plant Physiology, 165(2), 182-191. http://dx.doi.org/10.1016/j.jplph.2007.03.002. PMid:17499387.

Zhong, Y. G., \& Zhu, B. W. (2004). Study on postharvest physiology and fresh keeping of cherry fruit. Beifang Yuanyi, 2, 67-68.

Zhou, R., \& Wu, Q. (2018). Simulate the effects of different levels of road transportation vibration on the softening and pectin degradation of cantaloupe. Zhejiang Journal of Agricultural Sciences, 30, 1832-1838. 